\title{
Risks in the energy sector: the analysis of management practices in the electricity market
}

\author{
$Y$ Zhilkina $^{1, *}$ and $A$ Akhmetshin ${ }^{2}$ \\ ${ }^{1}$ Federal Grid Company of Unified Energy System, Russia, 117630, Moscow, st. Akademika Chelomeya, 5A \\ ${ }^{2}$ Kazan State Power Engineering University, Russia, 420066, Kazan, st. Krasnoselskaya, 51
}

\begin{abstract}
Energy security is today one of the most discussed event in international economic relations. It is being actively discussed by all governments and leading international organizations. There doesn't exist any universal definition of energy sector. In addition to the lack of such a universal definition, analysis of decisions in this area, one notices the lack of attention to such phenomena as risks in the energy sector, especially in the management of investment projects in the industry. For most industrial countries, energy insecurity means import dependency and aging infrastructure, while many emerging economies have additional vulnerabilities such as insufficient capacity, high energy intensity, and rapid demand growth. In many low-income countries, multiple vulnerabilities overlap, making them especially insecure.
\end{abstract}

\section{Introduction}

In the Energy Sector, critical infrastructure security and resilience goals and priorities are developed and achieved through a collaborative effort between the industry and the government. These goals include assessing security risks and threats, securing critical infrastructure from all hazards, enhancing critical infrastructure resilience, sharing information, and promoting learning and adaptation. There are numerous activities and programs that support these goals, developed and maintained by a wide variety of public and private organizations. Because the vast majority of energy infrastructure is owned and operated by the private sector, the Energy Sector security and resilience efforts are a shared responsibility between the public and private sectors. This section highlights some of the approaches and efforts that are underway in the Energy Sector to help achieve the national critical infrastructure security and resilience goals [1].

Throughout history, energy security has been viewed as protection from disruptions of essential energy systems. The notion of "essential energy systems" evolved from supplies of oil for military purposes to encompass various energy sources, infrastructure, and end-use sectors. The idea of "protection from disruptions" has also evolved from securing military or political control over energy resources to setting up complex policies and measures of strategically managing risks that affect all elements of energy systems. Though it is possible to discuss energy security at household, community, and other levels, most political concerns and scholarly research are about energy security of individual countries. This is because nation-states have a historic responsibility for security, national energy

systems provide appropriate units of analysis of key risks and vulnerabilities, and the majority of policy interventions to maintain energy security occur at the national level. Consequently, the analysis presented in this chapter primarily concentrates on the national level of energy security. [2-4]

Life safety is the state of security of the material world and human society from the negative impacts of various kinds. Its objects can be classified as follows are nature and society (see Figure 1).

Uninterrupted provision of vital energy services -

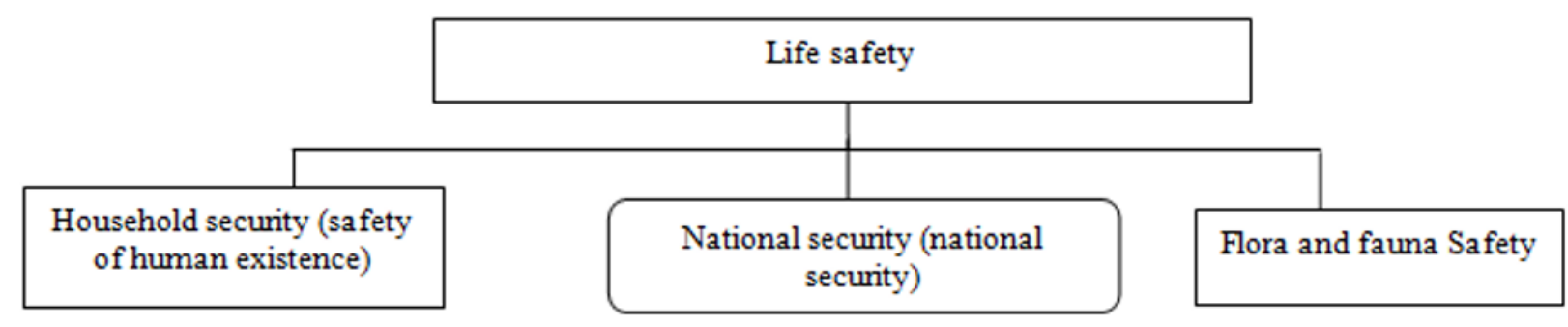

Fig. 1. The structure of the safety.

\footnotetext{
* Corresponding author: zhilkina.yulia@ gmail.com
} 
energy security - is a high priority of every nation. Energy security concerns are a key driving force of energy policy. These concerns relate to the robustness (sufficiency of resources, reliability of infrastructure, and stable and affordable prices); sovereignty (protection from potential threats from external agents); and resilience (the ability to withstand diverse disruptions) of energy systems.

Our analysis of energy security issues in over 130 countries shows that the absolute majority of them are vulnerable from at least one of these three perspectives $[5,6]$.

\section{The measures ensuring energy security of Russia}

Thus, energy security - is, first, the security of the energy complex, the lack of significant threats to its existence, and secondly, the lack of energy threats to the life of individuals and their various communities and organizations at the macro level. Energy security includes both a low level of security threats to the functioning and development of the energy complex of the country, and a low level of probability of threats to the development of society from the energy complex itself. These threats are closely associated with the problems of prevention and liquidation of emergency situations at the facilities of the energy complex of the country. The measures ensuring energy security of Russia includes measures on prevention of emergency situations through accidents or acts of sabotage at power facilities in peacetime and wartime and in case of their occurrence - measures for liquidation of emergency situations, security and protection of population, environment and decreasing material losses.[7-11]

Energy security meets the needs of the individual, society, state in the field of energy. The material and technical basis for its provision is the fuel and energy complex (FEC) of the Russian Federation. Thus, the energy aspects of national security are a broader concept than energy security and include the latter. Schematically, the relationship of concepts is shown in fig. 2 .

\section{Analysis of the main threats}

In the nature of risk and his omnipresence across every field of effort and mitigation, management and supervising risk, involved with matters of financial nature requires a discipline dedicated towards this end. Identifies 3 types of risk:

1.Risks that an organisation can face with a result to environmental changes. Theses changes target factors such as changes to interest rates, market and change rates.

2.Risks born outside an organisation's engagement and interaction with other organisations. These engagements involve things like horizontally and vertically transactions with sellers, customers and other parties.

3.Risks arising from an organisation and target specifically people processes and internal systems of the organisation. [12].

As objects are:

- individual, society and state;

- certain types of resources: natural, material (objects of labor), means of production, labor, financial, organizational and managerial resources of production activities, spheres and sectors of the economy, such as production, distribution, exchange and consumption, industries and sub-sectors of the national economy, markets for various goods and services [13].

Processes as subjects of threats can be: macro - and microeconomic processes; processes of technical and economic, organizational,managerial and socioeconomic changes; processes of production, distribution, exchange and consumption, saving, accumulation and investment, innovation processes and General processes of formation, development, degradation, etc [14].

Financial risk management is looking to give an answer and understand as how the risks cited above can affect organisations. If take financial risk management as a discipline, it is concerned with managing exposure to risk cited above in general, and also help organisations with market's sensibility risks and credit risks. Financial risk management as "a process to deal with the uncertainties resulting from financial markets".

The authors simply define and state that risk

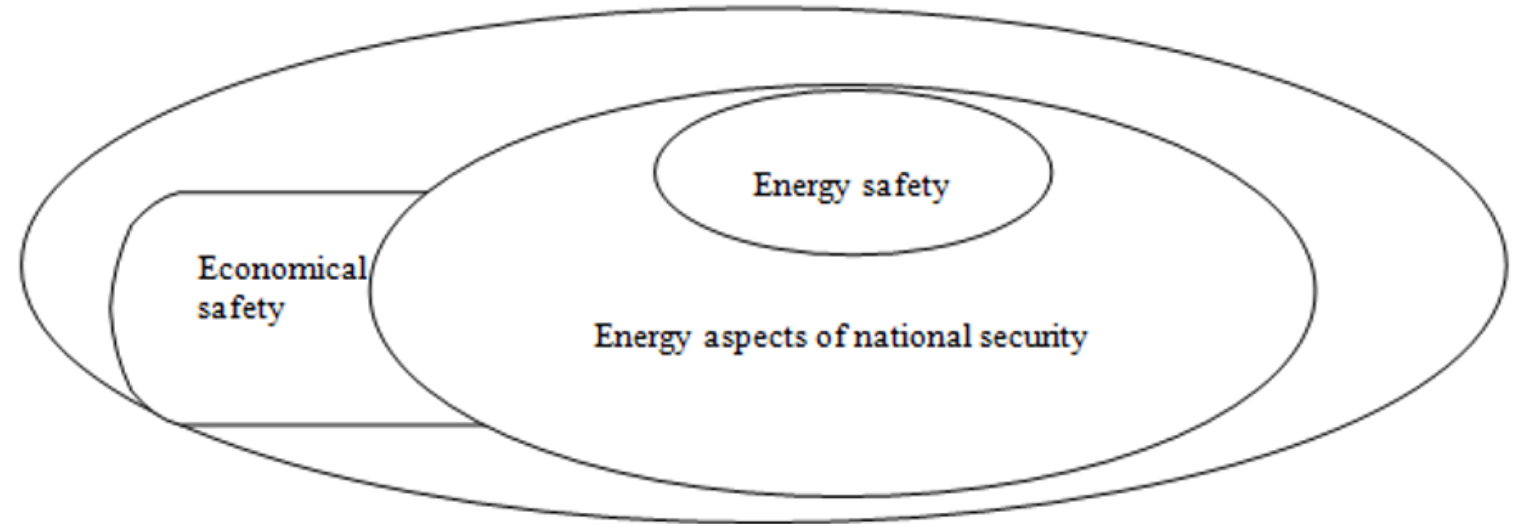

Fig. 2. Types of security. 
management is "the continual process of risk reduction" and of which financial risk management is "really about how firms actively select the type and level of risk that it appropriate for them to assure". As we can see, the attempt to define the topic appear with different factors, the author would suggest that the difference is superficial and simply differ as to the level of detail at which the definition is provided.

Financial risk management does not exclude the need to engage in risky activities and therefore risk management and risks that have been take are not mutually exclusive. The accentuation is about deciding which risks to assure, by which is meant against which types of risk will assurance be given.

In this context, the term assurance means the capability of providing an assessment of these risks and also providing information that organisation can count to make decisions that preoccupy them. Therefore, the purpose of the activity is about providing information, based upon analysis and estimates, as to the level of reward in relation to risks that are endemic to any business operation. [15].

The state of the national economy, the imperfection of the system of organization of state power and civil society, the socio-political polarization of Russian society and the criminalization of social relations, the growth of organized crime and the increase in the scale of terrorism, the aggravation of international relations and the complication of international relations create a wide range of internal and external threats to the national security of the country.

In the economic sphere, the threats are complex and are primarily due to a significant reduction in the gross domestic product, a decrease in investment, innovation and scientific and technical potential, stagnation of the agricultural sector, an imbalance in the banking system, an increase in external and domestic public debt, a tendency to dominate in the export of fuel and energy components, and in imports - food and consumer goods, including basic necessities.

The weakening of the country's scientific, technical and technological potential, the reduction of research in strategically important areas of scientific and technological development, the outflow of specialists and intellectual property threaten Russia with the loss of leading positions in the world, the degradation of science-intensive industries, the strengthening of external technological dependence and the undermining of Russia's defense capability .

The current threats to the energy security of the Russian Federation was analyzing, the author considers it legitimate to highlight the main ones:

- reduction of natural fuel and energy resources;

- inefficient state policy in the field of energy;

- lack of investment resources;

- equipment aging;

- man-made and natural threats;

- terrorism;

- increased pressure on the environment;

- critical state of the scientific and design industry complex;

- foreign economic threats.
Thus, based on the real situation in the country, taking into account global energy trends, Russia needs to attract investment for the integrated development of mineral and non-traditional resources of the regions. Investment is a vital need for the energy security of the Russian Federation. In this regard, you should pay attention to the risks.

\section{Economic risks}

First of all, some clarification of the concept of «risk» is required. Risk - an event that can occur under uncertainty with some probability, with three possible economic results, estimated in economic and financial indicators:

- negative - damage, loss, loss;

- positive - a gain, profit, win;

- zero - no harm, no gain.

The existence of risk is associated with the inability to predict the future with $100 \%$ accuracy. Based on this, it is necessary to highlight the main property of risk: risk occurs only in relation to the future and is inextricably linked to forecasting and planning, and hence to decision-making in General (the word «risk» literally means «decision-making», the result of which is unknown). It is also worth noting that the categories «risk» and «uncertainty» are closely related and are often used as synonyms.

However, it is useful to distinguish between «risk» and «uncertainty».

First, risk occurs only when a decision is necessary (if it is not, there is no point in taking the risk). In other words, it is the need to make decisions in the face of uncertainty that generates risk, in the absence of such a need, and there is no risk.

Second, risk is subjective and uncertainty is objective. For example, an objective lack of reliable information on the potential volume of electricity demand leads to a range of risks for project participants.

Risk assessment should take into account individual risk tolerance, which is described by indifference or utility curves. Therefore, it is recommended to describe the risk with the three above parameters:

$$
\text { Risk }=\{P * L * Y\}
$$

\section{Risks in PJSC «ROSSETI»}

Industry risk. Power industry is an infrastructural branch of the economy. The majority of end users of the industry products are located in the Russian Federation. Thus, the projected dynamics of the industry is determined by the overall dynamics of socio-economic development of all other sectors of the economy of the Russian Federation, as well as to some extent - climatic (water content levels) and weather (average annual temperature) conditions in Russia.

Country risk. The economy of the Russian Federation is still characterized by some features of the emerging market, in particular: the non-convertibility of the Russian ruble in most countries, currency control, as 
well as the level of inflation. The existing russian tax, currency and customs legislation is subject to varying interpretations and frequent changes.

Economic risk. Economic factors are overwhelmingly beyond the Issuer's control. Although the economic situation has shown signs of improvement, the economic Outlook of the Russian Federation depends largely on the effectiveness of economic measures, financial mechanisms and monetary policies undertaken by the Government, as well as the development of fiscal, legal and political systems.

Financial risk. Servicing of previously attracted loans and borrowings by PJSC «Rosseti» is carried out strictly in accordance with the established service schedules or ahead of them.

Environmental risk. Taking into account the current activities of PJSC «Rosseti», the risks are associated with the implementation of investment programs approved by the Board of Directors, in terms of compliance with the norms in construction.

\section{Conclusion}

World experience shows that there is no single, optimal organizational structure for all. It is necessary to choose the management structure that is adequate to the current economic conditions of the company and allows it to achieve its goals. Within any structure, emphasis can be placed on the decentralization of authority, allowing decision-makers at lower levels to make their own decisions. Decentralized structures are recommended when a company has access to dynamic markets, diversified production, competitors, and rapidly changing technologies. Methods of project risk management in the power industry can and should become a means of effective implementation of projects at all levels of management - Federal, regional, local. It is hoped that the problem of minimizing risks in the energy sector will be reflected.

\section{References}

1. Decree of the President of the Russian Federation of May 13, 2019 № 216 “On Approving the Doctrine of the Energy Security of the Russian Federation".

2. Yu.V. Zhilkina, Economic mechanism of innovative management of energy security, III Manyakin readings. Materials of the international scientificpractical conference (2014)

3. A.V. Vasenkov, A.A. Prokhozhev, Security of Russia: modern understanding of security, 22 (1998)

4. M. Kerste, M. Gerritsen, J. Weda, B. Tieben, Systemic Risk in the Energy Sector - Is There Need for Financial Regulation?, Energy Policy, 78, (2015) (https://doi.org/10.1016/j.jebo.2017.09.013)

5. M. Beccali, M. Cellura, V. Lo Brano, A. Marvuglia, Forecasting daily urban electric load profiles using artificial neural networks, Journal on Energy Conversion and Management, 45(18), 2879 -2900 (2004)
6. S.M. Nikitenko, E.V. Goosen, The problems and prospects of the public-private partnership in the Russian fuel and energy sector, IOP Conference Series: Earth and Environmental Science, 53(1) (2017)

7. P. Burgherr, J. Giroux, M. Spada, Accidents in the Energy Sector and Energy Infrastructure Attacks in the Context of Energy Security, European Journal of Risk Regulation, 6(2), 271-283 (2015) (DOI: https://doi.org/10.1017/S1867299X00004578)

8. T. Grynko, T. Gviniashvili, Organisational and economic mechanism of business entities' innovative development management, Economic Annals-XXI (2017)

9. T.T. Tatietse, P. Villeneuve, J. Ngundam, F. Kenfack, Contribution to the analysis of urban residential electrical energy demand in developing countries, Energy, 27(6), 591-606 (2002)

10. M.N. Dudin, N.V. Lyasnikov, V.D. Sekerin, A.E. Gorokhova, T.P. Danko, O.A.Bank,Technological changes as the development factor of the global and Russian energy sector, International Journal of Energy Economics and Policy, 7(1), 209-215 (2017)

11. C. Muscas, Power quality monitoring in modern electric distribution systems, IEEE Instrum. Meas. Mag., 13(5),19-27 (2010)

12. M.H.J. Bollen, S. Bahramirad, A. Khodaei, Is there a place for power quality in the smart grid?, Proc. Int. Conf. Harmon. Qual. Power, 713-717 (2014)

13. I.A. Kapitonov, G.A. Taspenova, V.R. Meshkov, A.A. Shulus, Integration of small and middle-sized enterprises into large energy corporations as a factor of business sustainability, International Journal of Energy Economics and Policy, 7(2), 4452 (2017)

14. Y. Qiu, G. Colson, C. Grebitus, Risk preferences and purchase of energy-efficient technologies in the residential sector, Ecological Economics, 107, 14 (2014)

15. I.A. Kvasov, Mechanism for system management of innovative development, Research (2015) (DOI: 10.18323/2073-5073-2015-4-116-120). 